\title{
BIRDS OF EASTERN NORTH
}

\section{AMERICA: A PHOTOGRAPHIC GUIDE}

PAUL STERRY and BRIAN E. SMALL. 2009. Princeton University Press, Princeton, NJ. Paper: \$18.95 US. ISBN: 978-0691-13426-0. Cloth: \$45.00 US. ISBN: 9780691-13425-3. 336 pages. $13.5 \times 21 \mathrm{~cm}$. 1118 colour photos. 406 maps.

\section{BIRDS OF WESTERN NORTH AMERICA: A PHOTOGRAPHIC GUIDE}

PAUL STERRY and BRIAN E. SMALL. 2009. Princeton University Press, Princeton, NJ. Paper: $\$ 18.95$ US. ISBN: 978-0691-13428-4. Cloth: $\$ 45.00$ US. ISBN: 9780691-13427-7. 416 pages. $13.5 \times 21 \mathrm{~cm} .1341$ colour photos. 449 maps.

In this review, I will examine both the eastern and western editions of the photographic guide to the birds of North America by Paul Sterry and Brian E. Small. The two books are very similar in format and overall content.

The first chapter in both editions is the Introduction. In this chapter, species and photo selections for the book, instructions on how to use the book, bird topography, glossary of 33 bird terms, brief discussion of plumage, bird identification, and bird migration, and a large section on bird habitats with photos of example habitats and typical bird species are included. This section is most useful to beginner birders and first-time users of these bird guides. I highly recommend reading the section on how to use these books before you use the guides for the first time.

Of course, the bulk of both books comprises species descriptions and digital photos. Species are presented by order and family with a few exceptions where superficially similar species are placed together. Species descriptions are placed on the left-hand page, with most of the corresponding digital photos on the right-hand page. Two or three species descriptions are placed on a page. At the end of the book, exotic and known feral introduced bird species are included with five to eight species descriptions per page. The eastern edition has 20 exotic and known feral introduced bird species while the western edition has about 35 exotic and known feral introduced bird species.

Species descriptions are brief, clearly and accurately written, with minimal ornithological jargon. The text is neatly matched with the corresponding digital photos. Differences between sexes, morphs, similar species, subspecies, seasonal plumages, and adults and juveniles are particularly well emphasized. Also included are voice (phonetic description of song and calls), status, and habitat and observation tips. These last two sections are designed to help birders increase their chances of seeing or hearing a bird species by identifying the best habitat types and seasons 


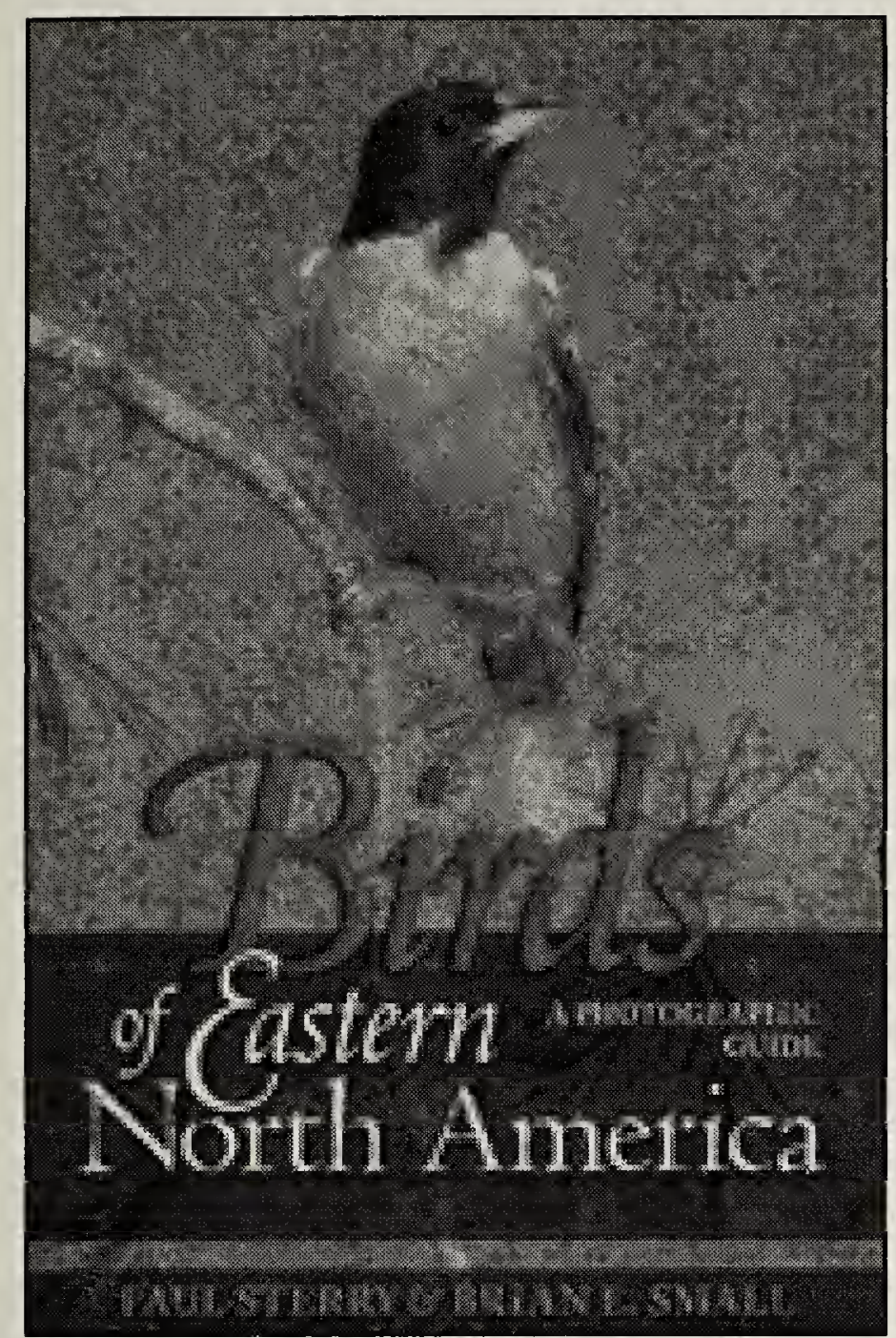

for species identification. The Cornell Laboratory of Ornithology prepared the clear, accurate, and current species range maps used in these two books.

The centrepieces of these bird guides are the digital photos. Unlike most other bird guides, they are not cut outs of birds pasted onto a simple white or coloured page. Instead, they are large cropped photos with natural backgrounds. A major drawback to this approach is the inability to include arrows and phrases to directly point to key identifying features of the bird in the photo. The digital photos in these two books are larger than photos in other bird guides such as the Kaufman Guide to Birds of North America. ${ }^{2}$ The photos are clear and sharp with attractive and simple captions and clearly show the beauty and key identifying features of the bird.

These guides are beautifully formatted and illustrated. The text size is large

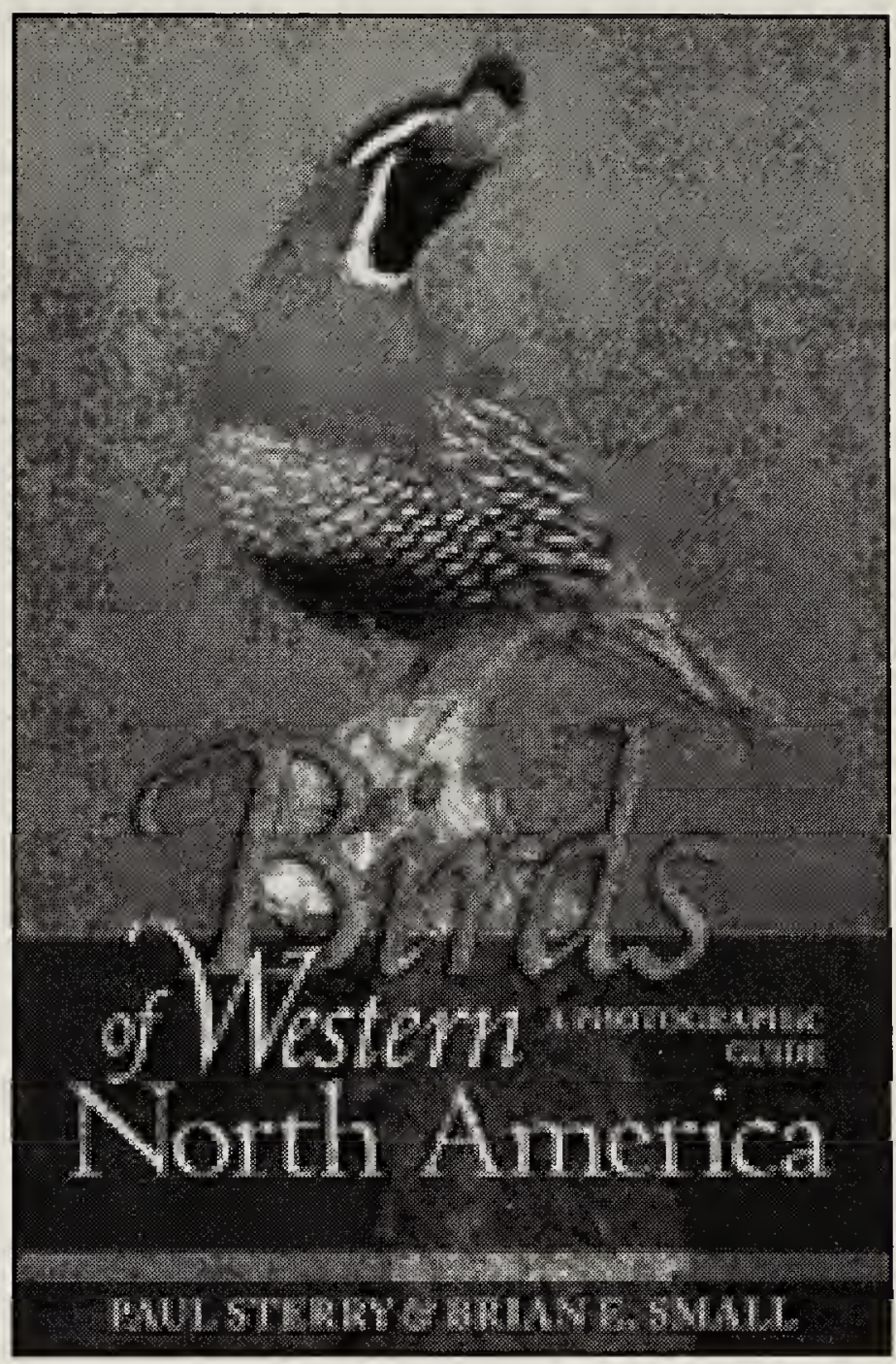

enough and the Arial font is clear and sharp for easy reading.

The question arises of which is better, digital photos or artist paintings (e.g. as in Sibley's Guide to Birds ${ }^{3}$ or National Geographic Birds of North America, 5th Edition $^{1}$ ) in field guides? When done properly, I feel that digital photos and artist paintings of birds both can be highly effective in assisting birders with bird identification. Although use of digital photos in bird guides has increased considerably in recent years, I still like both approaches to bird guides.

A more detailed Table of Contents in these books with the species accounts divided by bird family would have been very helpful in finding species more easily and more quickly. There is a detailed Index with common and scientific bird names that makes searching for a specific species in these guides very easy. 
The Further Reading section contains addresses for seven birding websites and citations for 16 bird guides and birding books.

The major differences between the two editions include additional and different species, primarily in the American southwest in the western edition and some different bird and habitat examples in the Introduction. In the western edition, Western Meadowlark is used instead of Eastern Meadowlark as an example grassland species.

\section{The bottom line}

The western edition is a better value because it has more species descriptions and digital photos for the same price. If you like these guides, you should select the edition depending on which half of the continent that you do most of your birding. Either edition would work well for a Saskatchewan birder.
The authors state that these guides are "intended to cater to the needs of the keen birder - the sort of person whose enthusiasm is built on several years of experience". I completely agree with their statement. I would say that these guides are ideal for intermediate to experienced birders who prefer digital photos to artist paintings in their field guides.

1. DUNN, J.L. and ALDERFER J. 2006. Field Guide to the Birds of North America, Fifth Edition. National Geographic Books, Washington, DC.

2. KAUFMAN, K. 2000. Birds of North America. Houghton Mifflin Company, New York, NY.

3. SIBLEY, D.A. 2000. The Sibley Guide to Birds. Alfred A. Knopf, New York, NY.

- Reviewed by Rob Warnock, E-mail: <warnockr@accesscomm.ca>

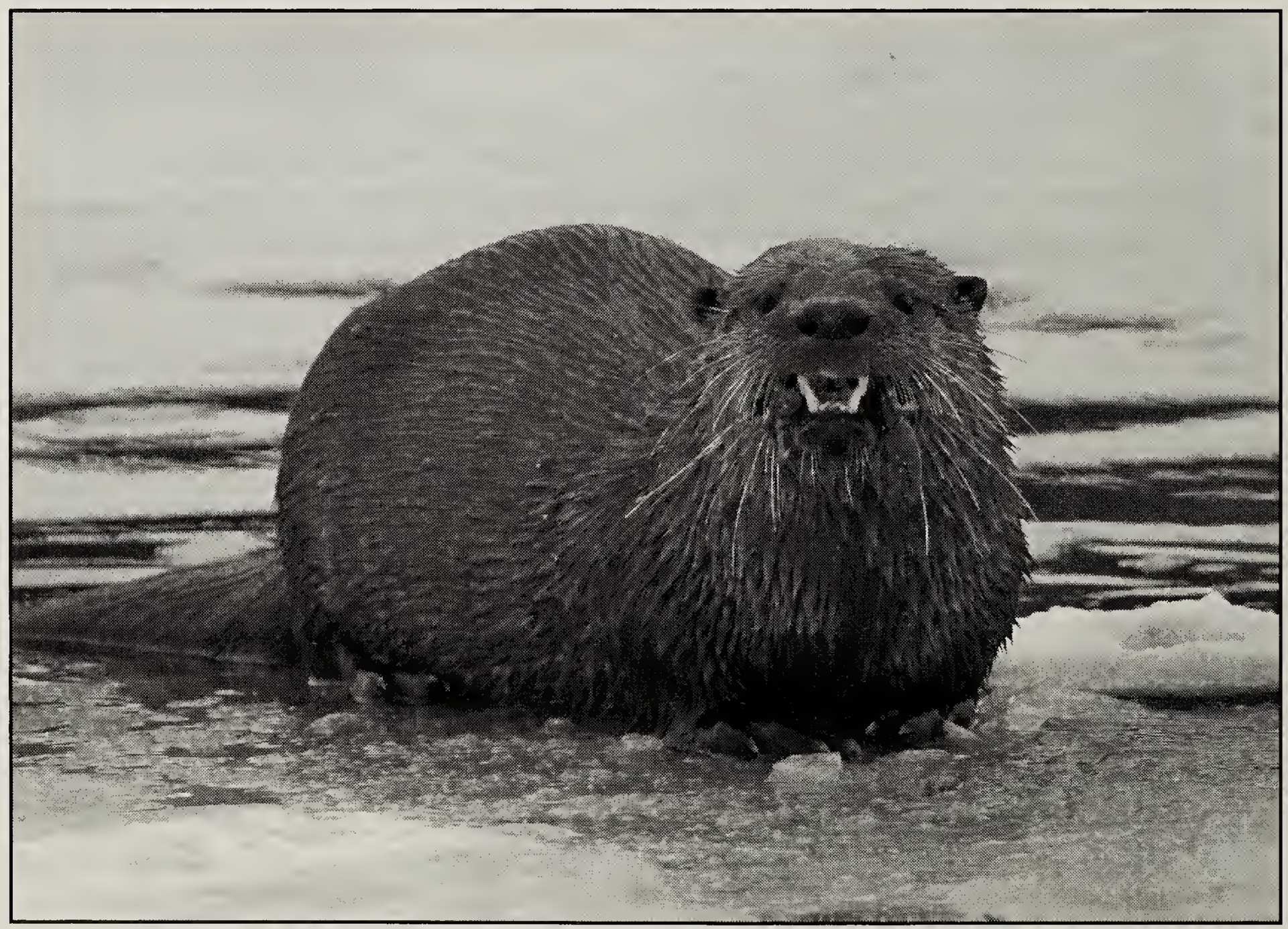

